\title{
iTRAQ-based comparative proteomic analysis provides insights into somatic embryogenesis in Gossypium hirsutum L.
}

\author{
Hua-Guo Zhu ${ }^{1} \cdot$ Wen-Han Cheng ${ }^{1,4} \cdot$ Wen-Gang Tian ${ }^{1} \cdot$ Yang-Jun $\mathrm{Li}^{1} \cdot$ Feng Liu $^{1} \cdot$ Fei Xue $^{1} \cdot$ Qian-Hao Zhu ${ }^{2}$. \\ Yu-Qiang Sun ${ }^{1,3} \cdot$ Jie Sun ${ }^{1}$
}

Received: 24 May 2017 / Accepted: 8 November 2017 / Published online: 6 December 2017

(c) The Author(s) 2017. This article is an open access publication

\begin{abstract}
Key message iTRAQ based proteomic identified key proteins and provided new insights into the molecular mechanisms underlying somatic embryogenesis in cotton.

Abstract Somatic embryogenesis, which involves cell dedifferentiation and redifferentiation, has been used as a model system for understanding molecular events of plant embryo development in vitro. In this study, we performed comparative proteomics analysis using samples of non-embryogenic callus (NEC), embryogenic callus (EC) and somatic embryo (SE) using the isobaric tags for relative and absolute quantitation (iTRAQ) technology. In total, 5892 proteins were identified amongst the three samples. The majority of these proteins (93.4\%) were found to have catalytic activity, binding activity, transporter activity or structural molecular activity. Of these proteins, 1024 and 858 were differentially expressed in NEC versus EC and EC versus SE, respectively. Compared to NEC, EC had 452 and 572 down- and up-regulated proteins, respectively, and compared to EC, SE had 647 and 221 down- and up-regulated proteins, respectively. KEGG (Kyoto Encyclopedia of Genes and Genomes) analysis indicated that genetic information transmission, plant hormone transduction, glycolysis, fatty acid biosynthesis and metabolism, galactose metabolism were the top pathways involved in somatic embryogenesis. Our proteomics results not only confirmed our previous transcriptomic results on the role of the polyamine metabolic pathways and stress responses in cotton somatic embryogenesis, but identified key proteins important for cotton somatic embryogenesis and provided new insights into the molecular mechanisms underlying somatic embryogenesis in cotton.
\end{abstract}

Keywords Gossypium hirsutum L. · Proteomic · Somatic embryogenesis · Polyamines · Stress-response

\section{Introduction}

Upland cotton (Gossypium hirsutum L.) is one of the most important economic crops, and the earliest commercialized transgenic crop worldwide. Above $70 \%$ cotton cultivars now used in China contains pest-resistant genes that were transformed by the Agrobacterium-mediated method (Zhang et al. 2015).

Hua-Guo Zhu and Wen-Han Cheng are co-first authors and have they contributed equally in this study.

Yu-Qiang Sun

sunyuq1109@hotmail.com

Jie Sun

sunjie@shzu.edu.cn

Extended author information available on the last page of the article
Somatic embryogenesis (SEM) not only provides a technique for gene transformation, but also serves as a model system for study of zygotic embryo development in plants (Yang and Zhang 2010; Zimmerman 1993). Transition from non-embryogenic calli (NEC) to embryogenic calli (EC), and from EC to somatic embryo (SE) are the two key steps of SEM. In cotton, plant regeneration via SEM occurs in only few genotypes, which leads to low efficiency in gene function study and development of new cultivars through Agrobacterium-mediated transformation.

Many studies have investigated physiological and biochemical changes during SEM in various plant species with a focus on understanding the mechanisms of gene regulation related to SEM. These efforts identified genes differentially expressed in somatic embryos, highlighted the pathways likely to be involved in SEM and discovered DNA or protein markers for SEM (Mantiri et al. 2008). SOMATIC EMBRYOGENESIS RECEPTOR-LIKE KINASE (SERK) from Daucus 
carota was the first identified marker gene with a crucial role in SEM (Schmidt et al. 1997). Subsequently, a number of genes differentially expressed during SEM that are related to auxin synthesis, transport, metabolism, signaling and stress responses were reported (Jiménez 2005; Jiménez and Thomas 2006; Jin et al. 2014; Thomas et al. 2002; Yang et al. 2012; Zeng et al. 2007). The roles of several genes in SEM have been well-characterized, including WUSCHEL (Zuo et al. 2002), LEAFY COTYLEDON (LEC) (Gaj et al. 2005), Arabinogalactan protein 1 (AGPl) (Letarte et al. 2006), Glutathione-S-transferase (GST) (Singla et al. 2007), SOMATIC EMBRYO RELATED FACTORI (MtSERF1) (Mantiri et al. 2008), BABY BOOM (BBM) (Kulinska-Lukaszek et al. 2012) and Agamous-like 15 (AGL15) (Yang et al. 2014; Zheng et al. 2013). Recently, a global transcriptome analysis of Arabidopsis embryogenesis provided a foundation for future research on genetic and epigenetic control of plant embryogenesis (Wickramasuriya and Dunwell 2015). On the other hand, molecular marker technology has been applied to identify quantitative trait loci related to SEM in upland cotton (Xu et al. 2015; Zhang et al. 2011). Furthermore, proteomic profile analysis has also been applied to study molecular mechanism of SEM in some plants (Bian et al. 2010; Heringer et al. 2015; Sun et al. 2013; Tan et al. 2013; Vale et al. 2014; Zhao et al. 2015). In cotton, a comparison of proteome dynamics between globular and cotyledonary embryos indicated that stress response, hormone homeostasis, and respiration and photosynthesis determined somatic embryo differentiation (Ge et al. 2014). These studies described the expression changes of a large number of genes or proteins during SEM and provided abundant clues for elucidation of the molecular mechanisms underlying SEM.

In this study, the isobaric tags for relative and absolute quantitation (iTRAQ) approach was applied to study proteome changes and to identify differentially accumulated proteins (DAPs) amongst the three key SEM stages in cotton, including NEC, EC and SE. Through identification and annotation of DAPs, we uncovered the key genes/proteins and pathways involved in cotton SEM. The results generated in this study provide a valuable foundation for further investigation of the roles of DAPs in cotton SEM.

\section{Materials and methods}

\section{Plant materials}

Seeds of cotton cultivar Xinluzao 33 (G. hirsutum L.) were decoated and imbibed in $0.1 \%$ (w/v) $\mathrm{HgCl}_{2}$ for $10 \mathrm{~min}$, then rinsed three times by sterile distilled water. Seeds were germinated aseptically in jam jars containing $1 / 2$ MS medium (Murashige and Skoog 1962). Hypocotyl sections (6-8 mm) from 6 days-old seedlings were used as explants for callus induction. The explants were cultured in MSB supplemented with $0.1 \mathrm{mg} / \mathrm{L} 2,4-\mathrm{D}$ and $0.1 \mathrm{mg} / \mathrm{L}$ Kinetin (KT), and subcultured monthly. Samples were collected from the following three stages of SEM (1) NEC from explants cultured in MSB for 45 days, (2) induced EC and (3) SEs including globular, heart, torpedo and cotyledonary embryos. The collected samples were immediately frozen in liquid nitrogen, and stored at $-80^{\circ} \mathrm{C}$ before protein extraction. Each sample was repeated three times. Culture mediums used in this study was listed in our previously published paper (Cheng et al. 2015).

\section{Protein preparation}

Samples were ground into powder in liquid nitrogen and extracted with lysis buffer (7 M urea, $2 \mathrm{M}$ thiourea, $4 \%$ CHAPS, 40 mM Tris-HCl, pH 8.5) containing 1 mM PMSF and $2 \mathrm{mM}$ (final concentration) EDTA. After $5 \mathrm{~min}, 10 \mathrm{mM}$ (final concentration) DTT was added to the samples. The suspension was sonicated at $200 \mathrm{~W}$ for $15 \mathrm{~min}$ and then centrifuged at $30,000 \times g$ for $15 \mathrm{~min}$ at $4{ }^{\circ} \mathrm{C}$. The supernatant was mixed well with $5 \times$ volume of chilled acetone containing $10 \%(\mathrm{v} / \mathrm{v}) \mathrm{TCA}$. After overnight incubation at $-20{ }^{\circ} \mathrm{C}$, the samples were centrifuged at $30,000 \times g$ for $5 \mathrm{~min}$ at $4{ }^{\circ} \mathrm{C}$, and the supernatant was discarded. The precipitate was washed three times with chilled acetone. After air-dry, the pellet was dissolved in lysis buffer (7 M urea, $2 \mathrm{M}$ thiourea, $4 \%$ NP40, 20 mM Tris-HCl, pH 8.0-8.5). The suspension was sonicated at $200 \mathrm{~W}$ for $15 \mathrm{~min}$ and centrifuged at $30000 \times \mathrm{g}$ for $15 \mathrm{~min}$ at $4{ }^{\circ} \mathrm{C}$. The supernatant was then transferred to another tube. To reduce disulfide bonds in proteins, $10 \mathrm{mM}$ (final concentration) DTT was added and incubated at $56^{\circ} \mathrm{C}$ for $1 \mathrm{~h}$. Subsequently, $55 \mathrm{mM}$ (final concentration) IAM was added and incubated for $1 \mathrm{~h}$ in the darkroom to block cysteines. The supernatant was then mixed well with $5 \times$ volume of chilled acetone for $2 \mathrm{~h}$ at $-20{ }^{\circ} \mathrm{C}$ to precipitate proteins. After centrifugation at $30000 \times g$ for 5 min at $4{ }^{\circ} \mathrm{C}$, the supernatant was discarded. The pellet was dissolved in $500 \mu \mathrm{L}$ of $0.5 \mathrm{M}$ TEAB (Applied Biosystems, Milan, Italy) after $5 \mathrm{~min}$ of air-dry, and sonicated at $200 \mathrm{~W}$ for $15 \mathrm{~min}$. Finally, samples were centrifuged at $30,000 \times g$ for $15 \mathrm{~min}$ at $4{ }^{\circ} \mathrm{C}$. The supernatant, i.e. protein solution, was transferred to a new tube, quantified and then kept at $-80{ }^{\circ} \mathrm{C}$ before further analysis.

\section{iTRAQ labeling and SCX fractionation}

For each sample, $100 \mu \mathrm{g}$ of total protein was digested by Trypsin Gold (Promega, Madison, WI, USA) at $37{ }^{\circ} \mathrm{C}$ for $16 \mathrm{~h}$ with a ratio of protein:trypsin $=30: 1$. After trypsin digestion, the solutions were dried by vacuum centrifugation. Peptides were then reconstituted in $0.5 \mathrm{M}$ TEAB and processed using the 8-plex iTRAQ reagent kit according to 
the manufacture's protocol (Applied Biosystems). Briefly, one unit of ITRAQ reagent was thawed and reconstituted in $24 \mu \mathrm{L}$ isopropanol. Samples were labeled with the iTRAQ tags as follow: Sample NEC1/2 (114/116 tag), Sample EC1/2 (119/117 tag), Sample SE1/2 (118/121 tag). The isobaric tags labeled peptides were incubated at room temperature for $2 \mathrm{~h}$, then pooled and dried by vacuum centrifugation.

SCX chromatography was performed with a LC-20AB HPLC Pump system (Shimadzu, Kyoto, Japan). The iTRAQlabeled peptide mixtures were reconstituted with $4 \mathrm{~mL}$ buffer A ( $25 \mathrm{mM} \mathrm{NaH}_{2} \mathrm{PO}_{4}$ in $\left.25 \% \mathrm{ACN}, \mathrm{pH} 2.7\right)$ and loaded onto a $4.6 \times 250 \mathrm{~mm}$ Ultremex SCX column containing $5-\mu \mathrm{m}$ particles (Phenomenex). The peptides were eluted at a flow rate of $1 \mathrm{~mL} / \mathrm{min}$ with buffer A for $10 \mathrm{~min}, 5-60 \%$ buffer B (25 mM NaH $\mathrm{PO}_{4}, 1 \mathrm{M} \mathrm{KCl}$ in $\left.25 \% \mathrm{ACN}, \mathrm{pH} 2.7\right)$ for 27 min, $60-100 \%$ buffer B for $1 \mathrm{~min}$. The system was then maintained at $100 \%$ buffer B for 1 min before equilibrating with buffer A for 10 min prior to the next injection. Elution was monitored by measuring the absorbance at $214 \mathrm{~nm}$, and fractions were collected every $1 \mathrm{~min}$. The eluted peptides were pooled into 20 fractions, desalted with a Strata X C18 column (Phenomenex) and vacuum-dried.

\section{LC-ESI-MS/MS analysis based on Q EXACTIVE}

Each fraction was resuspended in buffer $\mathrm{C}$ ( $2 \% \mathrm{ACN}, 0.1 \%$ FA) and centrifuged at $20,000 \times g$ for $10 \mathrm{~min}$, the final concentration of peptide was about $0.5 \mu \mathrm{g} / \mu \mathrm{L}$ on average. $10 \mu \mathrm{L}$ supernatant was loaded on a LC-20AD nanoHPLC (Shimadzu, Kyoto, Japan) by the autosampler onto a $2 \mathrm{~cm} \mathrm{C18}$ trap column. Then, the peptides were eluted onto a $10 \mathrm{~cm}$ analytical C18 column (inner diameter $75 \mu \mathrm{m}$ ) packed inhouse. The samples were loaded at $8 \mu \mathrm{L} / \mathrm{min}$ for $4 \mathrm{~min}$, then the 44 min gradient was run at $300 \mathrm{~nL} / \mathrm{min}$ starting from 2 to $35 \%$ buffer D ( $98 \%$ ACN, 0.1\% FA), followed by $2 \mathrm{~min}$ linear gradient to $80 \%$, and maintained at $80 \%$ buffer $\mathrm{D}$ for 4 min, and finally return to $5 \%$ in $1 \mathrm{~min}$.

The peptides were subjected to nanoelectrospray ionization followed by tandem mass spectrometry (MS/MS) in a Q EXACTIVE (Thermo Fisher Scientific, San Jose, CA) coupled online to the HPLC. Intact peptides were detected in the Orbitrap at a resolution of 70,000. Peptides were selected for MS/MS using high-energy collision dissociation (HCD) operating mode with a normalized collision energy setting of 27.0; ion fragments were detected in the Orbitrap at a resolution of 17,500. A data-dependent procedure that alternated between one MS scan followed by $15 \mathrm{MS} / \mathrm{MS}$ scans was applied for the 15 most abundant precursor ions above a threshold ion count of 20,000 in the MS survey scan with a following Dynamic Exclusion duration of $15 \mathrm{~s}$. The electrospray voltage applied was $1.6 \mathrm{kV}$. Automatic gain control (AGC) was used to optimize the spectra generated by the Orbitrap. The AGC target for full
MS was $3 \mathrm{e} 6$ and $1 \mathrm{e} 5$ for MS2. For MS scans, the $\mathrm{m} / \mathrm{z}$ scan range was 350-2000 Da. For MS2 scans, the m/z scan range was 100-1800.

\section{Data analysis}

Raw data files acquired from the Orbitrap were converted into MGF files using Proteome Discoverer 1.2 (PD 1.2, Thermo), 5600 msconverter and the MGF file were searched. Protein identification was performed by using Mascot search engine (Matrix Science, London, UK; version 2.3.02) against the database.

For protein identification, a mass tolerance of 5 Da was permitted for intact peptide masses and $13 \mathrm{Da}$ for fragmented ions, with allowance for one missed cleavages in the trypsin digests. Gln->pyro-Glu (N-term Q), oxidation (M), deamidated (NQ) as the potential variable modifications, and carbamidomethyl (C), iTRAQ8plex (N-term), iTRAQ8plex (K) as fixed modifications. The charge states of peptides were set to +2 and +3 . Specifically, an automatic decoy database search was performed in Mascot by choosing the decoy checkbox in which a random sequence of database is generated and tested for raw spectra as well as the real database. To reduce the probability of false peptide identification, only peptides with significance scores $(\geq 20)$ greater than "identity" at the $99 \%$ confidence interval by a Mascot probability analysis were counted. And each confident protein was identified with at least one unique peptide.

The quantitative protein ratios were weighted and normalized by the median ratio in Mascot. We only used ratios with $\mathrm{p}$ values $<0.05$, and considered those with a fold change of $>1.5$ as significant.

\section{Protein function annotation}

Functional annotations of the proteins identified were conducted using the Blast2GO program against the non-redundant protein database (NR; NCBI). The KEGG database (http://www.genome.jp/kegg/) and the COG (Cluster of Orthologous Groups) database (http://www.ncbi.nlm.nih. gov/COG/) were used to classify and group the proteins. COG is the database for orthologous protein classification. Every protein in COG is supposed to derive from a same protein ancestor. KEGG pathway is a collection of manually drawn pathway maps representing our knowledge on the molecular interaction and reaction networks. Gene Ontology (GO) is an international standard of gene function classification, which provides a set of dynamic updating controlled vocabulary to describe attributes of genes and gene products. GO has three Ontologies describing molecular function, cellular component, and biological process. 


\section{RNA extraction and quantitative real-time PCR}

Total RNA was extracted from NEC, EC and SE of Xinluzao 33 using a modified cetyltrimethyl ammonium bromide (CTAB) method (Luo et al. 2003) and was stored at $-80^{\circ} \mathrm{C}$ before use. The quality of total RNA was checked on a $1 \%$ (w/v) ethidium bromide-stained agarose gel. $1 \mu \mathrm{g}$ aliquot of total RNA was used for the first-strand cDNA synthesis with the M-MLV reverse transcriptase (TaKaRa) following the manufacturer's instructions. Quantitative real-time PCR (qRT-PCR) was performed to detect gene expression level. The gene-specific primers used in qRT-PCR are listed in Table 1, and the cotton EF1 $\alpha$ gene was used as an internal control. The qRT-PCR assays were performed with SYBR Premix Ex Taq (TaKaRa) on an Mx3000p system (Agilent, USA). Each reaction $(25 \mu \mathrm{L})$ contained $4 \mu \mathrm{M}$ of each primer, $2 \mu \mathrm{L}$ of cDNA (1:100 diluted), and $10 \mu \mathrm{L}$ of PCR buffer for the Eva Green Master Mix. Thermal cycling conditions were pre-incubation at $95^{\circ} \mathrm{C}$ for $2 \mathrm{~min}$, followed by 40 cycles of $94{ }^{\circ} \mathrm{C}$ for $15 \mathrm{~s}, 56{ }^{\circ} \mathrm{C}$ for $20 \mathrm{~s}$, and $72{ }^{\circ} \mathrm{C}$ for $20 \mathrm{~s}$. Relative expression ratios of the target genes were calculated based on the standard equation (Bogs et al. 2005). The expression assay was performed using three independent biological replicates and each biological replicate was performed with three technical repeats.

\section{Results and discussion}

\section{Somatic embryogenesis in cotton cv Xinluzao 33}

Embryogenic callus (EC) of Xinluzao 33 was formed from non-embryogenic callus (NEC) after about 6 months of culture. Differentiation of somatic embryos (SEs) from embryogenic callus was the most restrictive step during cotton SEM and plantlet regeneration. To identify proteins with a key role in cotton SEM, we sampled NEC, EC and SEs for protein preparation and iTRAQ analysis (Fig. 1a-c).

\section{Protein identification by iTRAQ}

iTRAQ based comparative proteome was employed to assess protein changes amongst NEC, EC and SEs in cotton. In the three samples, a total of 379,894 (62,335 unique) spectra were obtained. Of these spectra, 19,965 were identified as peptides (16,647 unique peptides) and 5892 as proteins (Fig. 2a). The mass of the identified proteins showed a normal distribution, with $0-50,51-100$ and $>100 \mathrm{kDa}$ proteins accounting for 56, 32 and $11 \%$, respectively (Fig. 2b). The peptide number distribution of the proteins (number of amino acids) with $1-5$ peptides, $6-10$ peptides, and 11 or more peptides comprised 5160,569, and 163 , respectively

Table 1 Primers used in qRT-PCR

\begin{tabular}{lll}
\hline Gene accession & Sense primer & Antisense primer \\
\hline Unigene22318_All & 5'-ATCACCGACACCTACTCCCT-3' & 5'-GAACAGTTATCTCCCGACCA-3' \\
CL8598.Contig1_All & 5'-GCGGTGATTGGTCTGAGATG-3' & 5'-CGATGAGTTGTTGATTGGGTT-3' \\
CL12349.Contig2_All & 5'-CATTACGGGTCGTTTAGCC-3' & 5'-ATCTCCCAACTTGCATTCC-3' \\
CL543.Contig2_All & 5'-TGACATGCTGCCTTCGTTT-3' & 5'-CCCTGTATTGCTGTGACCC-3' \\
CL3039.Contig1_All & 5'-GAGATCACCTGTGAAGCGAGAA-3' & 5'-TCCCACTGTAATCCGAACCA-3' \\
CL2767.Contig2_All & 5'-TCCAGCCTCAGCAACCTAC-3' & 5'-GGTTTGAAGCCCAGGAGTG-3' \\
\hline
\end{tabular}

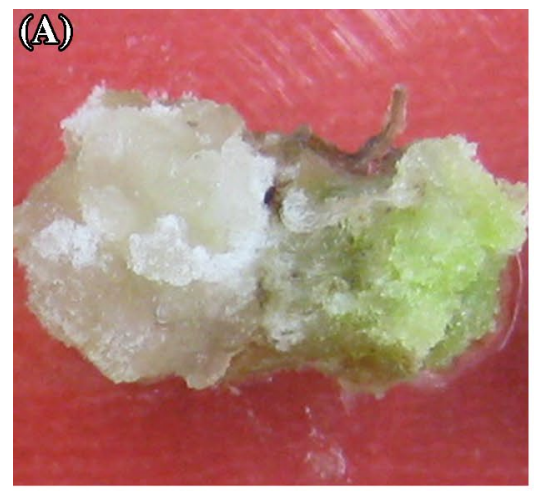

NEC

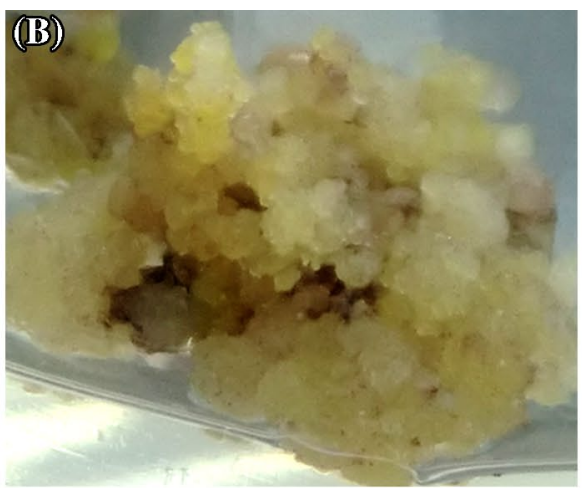

EC

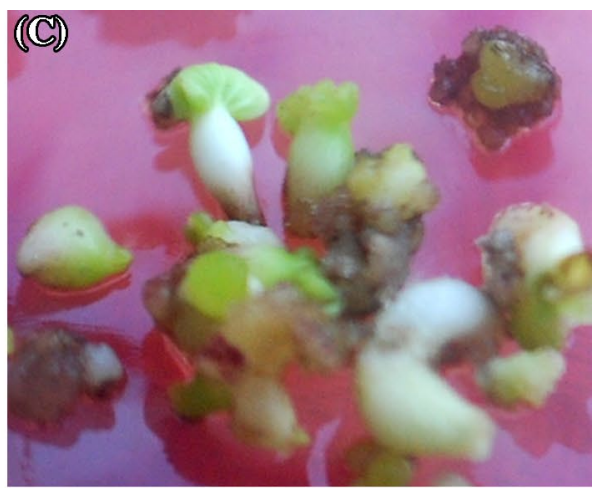

SE

Fig. 1 Samples used for proteomic assays. a 45-day non-embryogenic callus (NEC); b embryogenic callus (EC); c somatic embryos (SEs) 

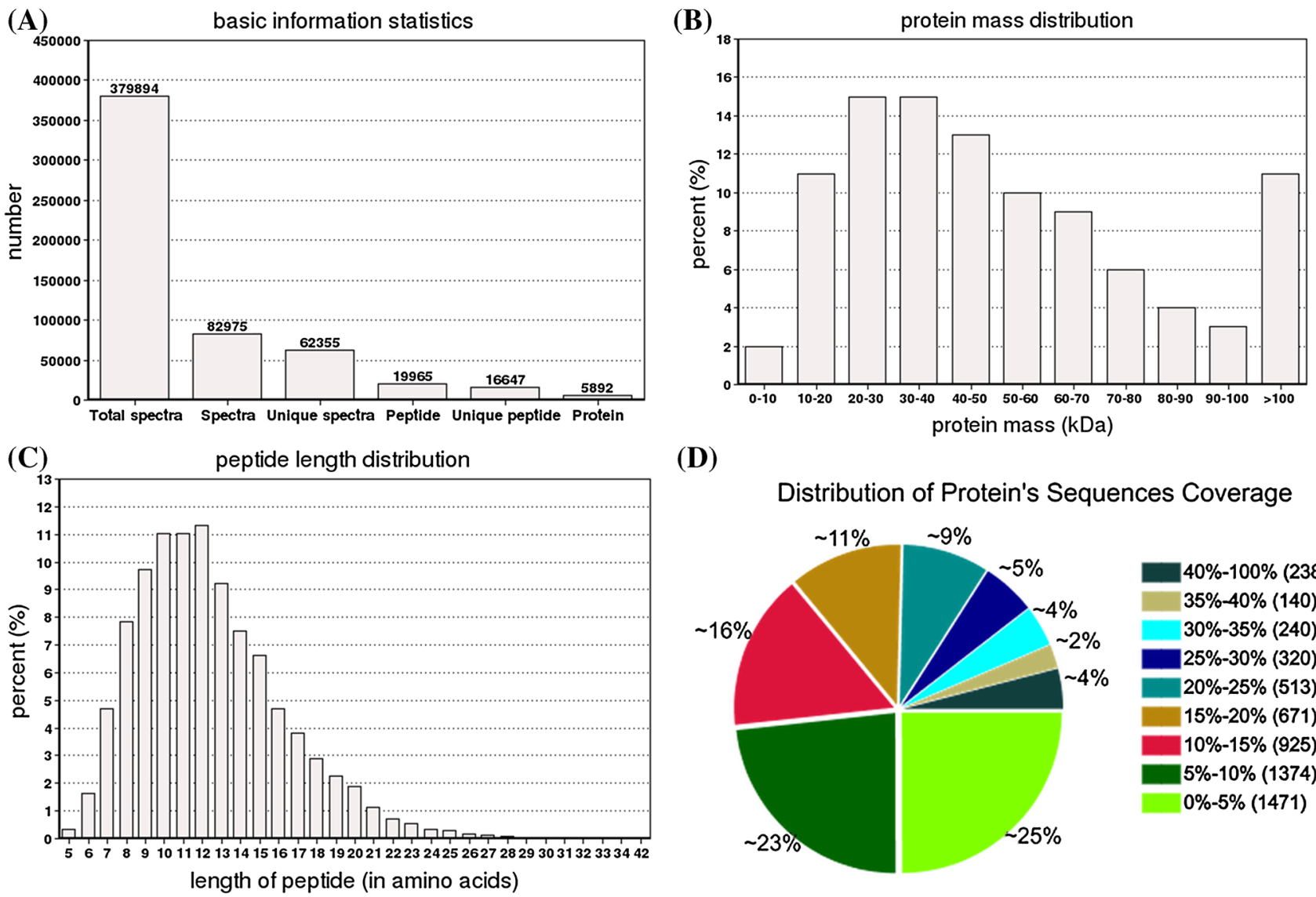

(D)
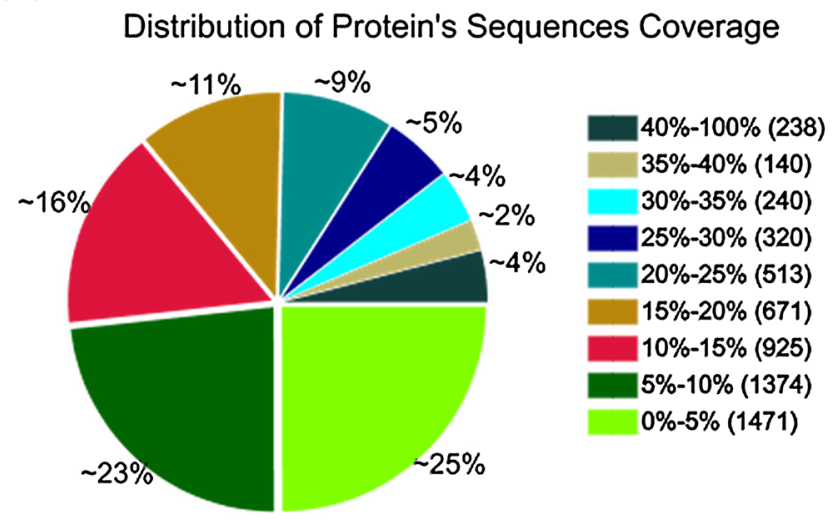

Fig. 2 Protein identification by iTRAQ. a Number of spectra, peptide and protein; $\mathbf{b}$ percentage of protein mass distribution; $\mathbf{c}$ peptide length distribution; $\mathbf{d}$ distribution of protein's sequence coverage

(Fig. 2c), most peptides have 9-13 amino acids, very few peptides have 5 or less amino acids. The distribution of protein sequence coverage with 40-100, 30-40, 20-30, 10-20, and under $10 \%$ variations accounted for $4.04,6.45,14.14$, 27.09 and $48.29 \%$, respectively (Fig. 2d).

\section{Functional categories of the proteins in GO and COG}

GO analysis was applied to annotate the 5892 proteins identified in NEC, EC and SEs. At the biological process level, proteins involved in metabolic process, cellular process, single-organism process and response to stimulus process accounted for $15.83,15.71,10.59$ and $8.96 \%$, respectively, and other proteins accounted for about $50 \%$. At the cellular component level, proteins related to cell, cell part, organelle, membrane and organelle part accounted for 23.39, 23.39, $18.88,9.98$ and $8.38 \%$, respectively, and others accounted for $14.38 \%$. At the molecular function level, proteins with catalytic activity, binding activity, transporter activity and structural molecular activity covered 44.14, 41.42, 4.37, and $3.47 \%$, respectively, and others covered $6.6 \%$ (Fig. 3a). Analysis of the identified proteins by COG suggested that general function prediction, posttranslational modification\ protein turnoverlchaperones, translation $\backslash$ ribosomal structure and biogenesis, carbohydrate transport and metabolism, energy production and conversion were the top five types of functions (Fig. 3b).

\section{Identification of differentially accumulated proteins}

Differentially accumulated proteins (DAPs) were defined as those with a $>1.5$-fold change in relative abundance $(\mathrm{P}<0.05)$ between NEC and EC, or between EC and SEs. In total, 1024 and 858 DAPs were identified in NEC versus EC, and EC versus SEs, respectively. Of the 1024 DAPs identified between NEC and EC, 452 and 572 proteins were down- and up-regulated in EC, respectively. Of the 858 DAPs identified between EC and SEs, 647 and 221 proteins were down- and up-regulated in SEs, respectively (Fig. 4a). Protein ratio distribution was focused in general function prediction, posttranslational modification /protein turnover। chaperones (Fig. 4b, c).

To investigate the overall dynamics of proteome changes in SEM of Xinluzao 33, we performed a hierarchical cluster 
(A)

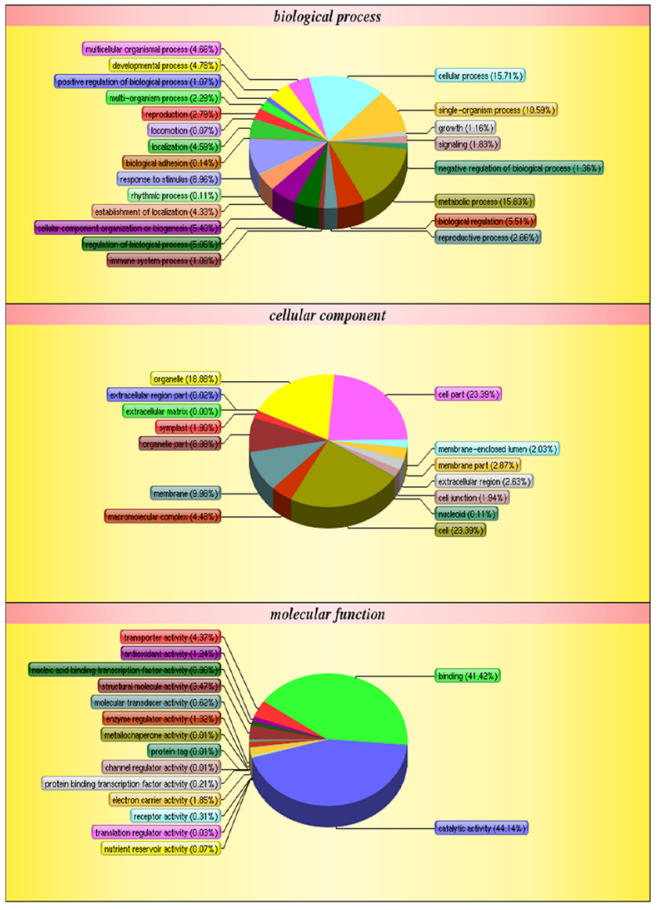

(B)

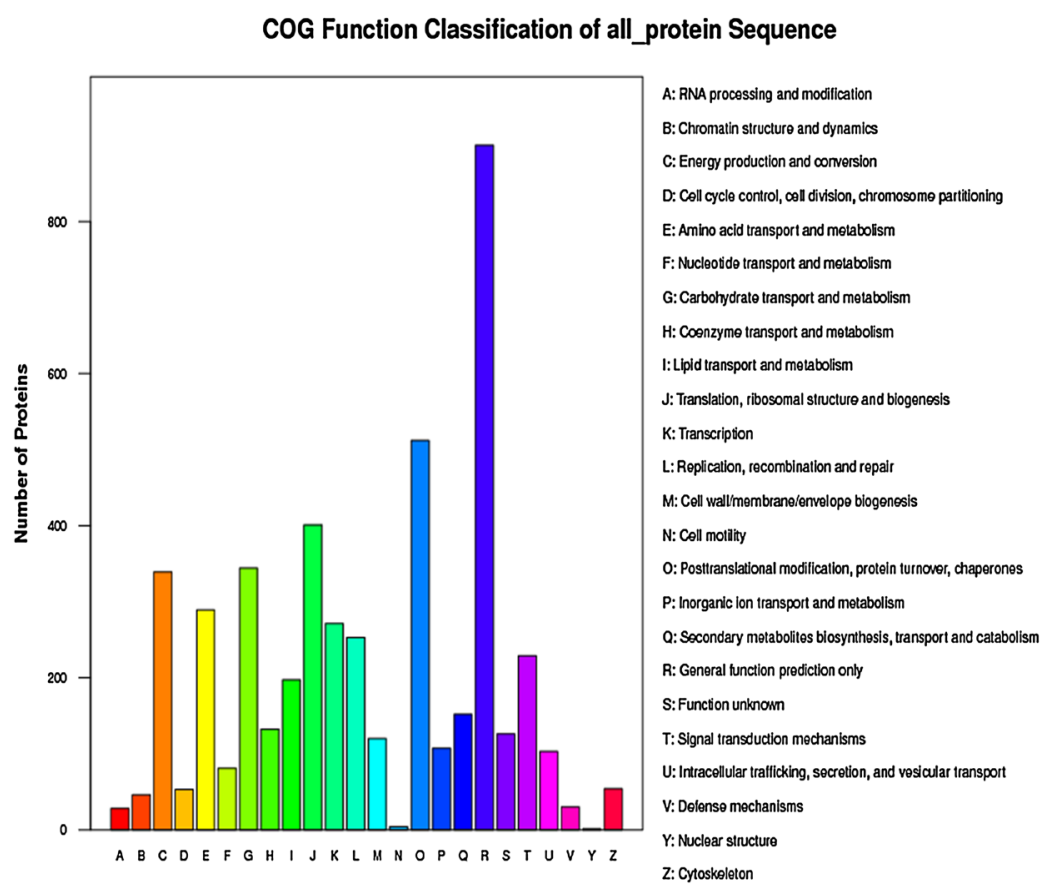

Fig. 3 GO and COG analysis of identified proteins in somatic embryogenesis. a GO analysis of DAPs; $\mathbf{b}$ COG analysis of DAPs
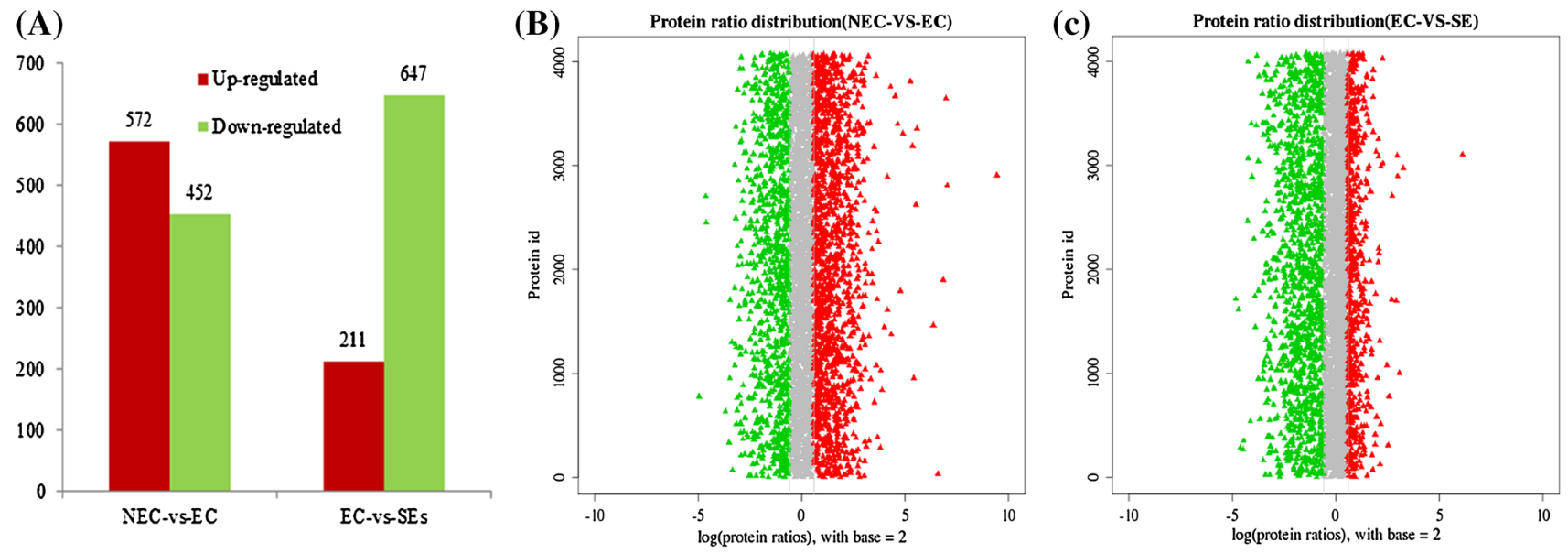

Fig. 4 Distribution of DAPs. a Number of up-and down-regulated DAPs in NEC vs. EC and EC vs. SEs; $\mathbf{b}$ and $\mathbf{c}$ protein ratio distribution in NEC vs. EC and EC vs. SEs, respectively

analysis for the DAPs identified in NEC, EC and SEs. This analysis suggested three types of protein expression patterns, i.e. up- to up-regulation, up- to down-regulation, and, downto up-regulation (Fig. 5).

\section{Pathway annotation of DAPs in KEGG}

The 1882 DAPs identified were classified into 127 families based on KEGG. About $48 \%$ of them were classified into metabolic pathways and biosynthesis of secondary metabolites, which suggests that metabolites were remarkably changed during SEM. Furthermore, about $2-5 \%$ of DAPs were involved in pathways related to ribosome, spliceosome, protein processing in endoplasmic reticulum, RNA transport, glycolysis/gluconeogenesis, plant hormone signal transduction, plant-pathogen interaction, mRNA surveillance pathway, starch and sucrose metabolism, purine metabolism, pyruvate metabolism, phenylpropanoid biosynthesis, amino 

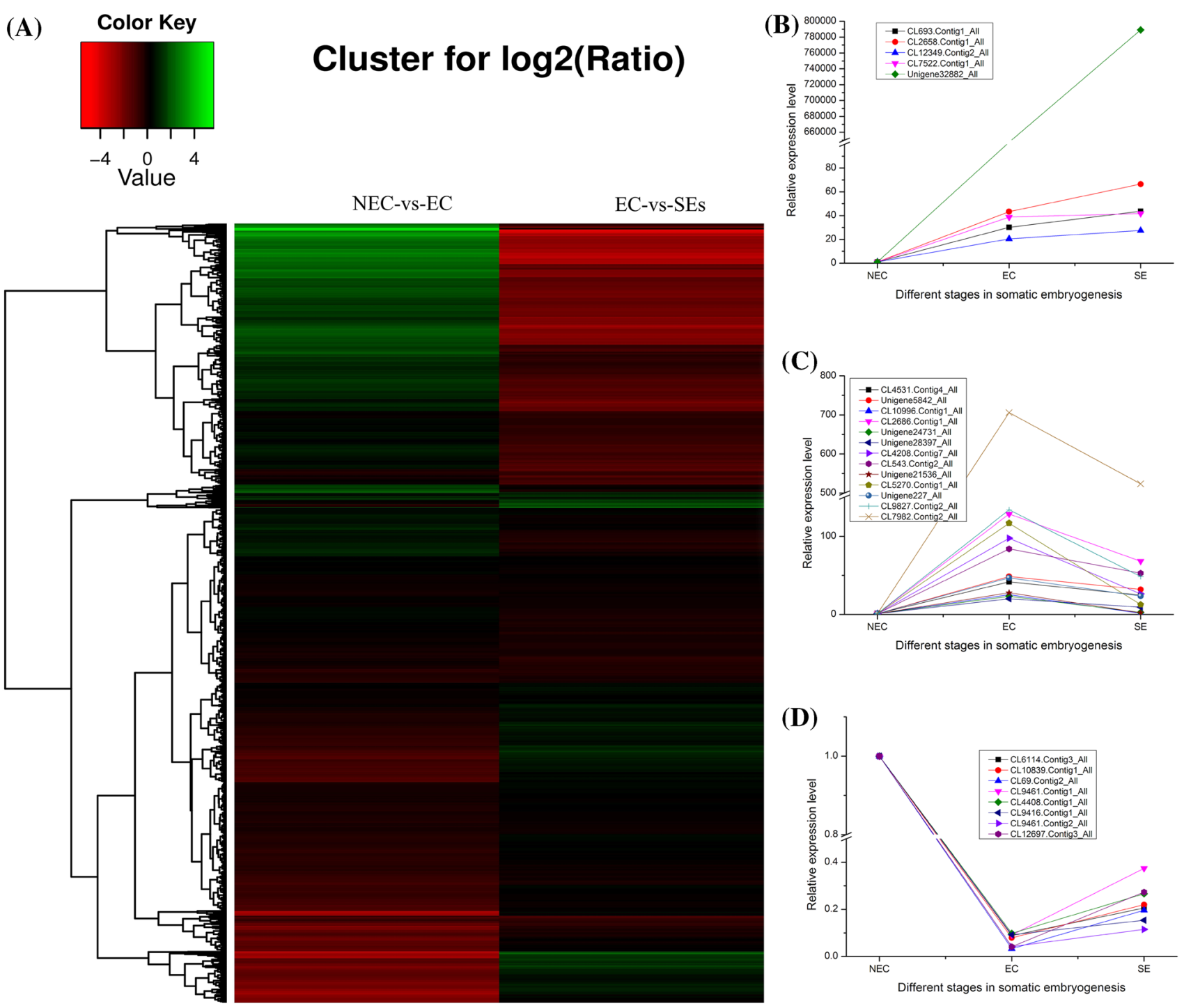

Fig. 5 Cluster analysis of DAPs in NEC, EC and SEs. a Cluster analysis of DAPs in NEC, EC and SEs; $\mathbf{b}$ representative DAPs showing continuous accumulation from NEC to EC, and from EC to SEs, i.e. with a pattern of up- to up-regulation; $\mathbf{c}$ representative DAPs show-

sugar and nucleotide sugar metabolism and oxidative phosphorylation. The aforementioned pathways covered more than $90 \%$ of the DAPs. Ribosome, spliceosome, protein processing in endoplasmic reticulum and RNA transport are involved in genetic information transcription and processing, which suggests that remarkable changes of genetic information occurred in SEM. We listed the top 25 pathways based on the number of DAPs in Table 2.

\section{Transcriptional analysis of candidate genes encoding DAPs}

To know the correlation between the expression levels of DAPs and their corresponding genes, we selected six ing accumulation from NEC to EC, but decrease from EC to SEs, i.e. with a pattern of up- to down-regulation; $\mathbf{d}$ representative DAPs showing decrease from NEC to EC, but increase from EC to SEs, i.e. with a pattern of down- to up-regulation

DAPs and analyzed their transcript levels in NEC, EC and SE. The six selected genes were CL543.Contig2_All (tubulin beta-1), CL12349.Contig2_All (conserved hypothetical protein), CL8598.Contig1_All (rRNA-processing protein fcf2-like isoform 1), CL3039.Contig1_All (serine/arginine-rich splicing factor RS2Z32-like isoform 1), CL2767.Contig2_All (uncharacterized protein At2g39795), and Unigene22318_All (serine/arginine rich splicing factor). Three genes, including CL8598.Contig1_All, CL12349.Contig2_All and Unigene22318_All, showed good correlation between the expression levels of protein and mRNA. For the other three DAPs, no good correlation between their expression levels of protein and mRNA was observed, suggesting that their protein levels 
Table 2 Pathway annotation of differentially accumulated proteins in somatic embryogenesis

\begin{tabular}{llrc}
\hline No. & Pathway & DAPs $(4172)$ \\
\hline 1 & Metabolic pathways & 1270 & $30.44 \%$ \\
2 & Biosynthesis of secondary metabolites & 736 & $17.64 \%$ \\
3 & Ribosome & 199 & $4.77 \%$ \\
4 & Spliceosome & 174 & $4.17 \%$ \\
5 & Protein processing in endoplasmic reticulum & 168 & $4.03 \%$ \\
6 & RNA transport & 167 & $4.00 \%$ \\
7 & Glycolysis/gluconeogenesis & 129 & $3.09 \%$ \\
8 & Plant hormone signal transduction & 121 & $2.90 \%$ \\
9 & Plant-pathogen interaction & 120 & $2.88 \%$ \\
10 & mRNA surveillance pathway & 111 & $2.66 \%$ \\
11 & Starch and sucrose metabolism & 110 & $2.64 \%$ \\
12 & Purine metabolism & 108 & $2.59 \%$ \\
13 & Pyruvate metabolism & 107 & $2.56 \%$ \\
14 & Phenylpropanoid biosynthesis & 100 & $2.40 \%$ \\
15 & Amino sugar and nucleotide sugar metabolism & 95 & $2.28 \%$ \\
16 & Oxidative phosphorylation & 90 & $2.16 \%$ \\
17 & Pyrimidine metabolism & 82 & $1.97 \%$ \\
18 & RNA degradation & 81 & $1.94 \%$ \\
19 & Endocytosis & 75 & $1.80 \%$ \\
20 & Carbon fixation in photosynthetic organisms & 74 & $1.77 \%$ \\
21 & Glutathione metabolism & 71 & $1.7 \%$ \\
22 & Peroxisome & 60 & $1.44 \%$ \\
23 & Ascorbate and aldarate metabolism & 57 & $1.37 \%$ \\
24 & Proteasome & 56 & $1.34 \%$ \\
25 & Arginine and proline metabolism & 53 & $1.27 \%$ \\
\hline & & & \\
& &
\end{tabular}

might be determined not only at the transcript level but also at the post-translational level (Fig. 6).

\section{SERK, LEC and CKI proteins are differentially accumulated during cotton SEM}

The SERK family genes and LEC1 (LEAFY COTYLE$D O N 1)$ were implicated in the signal transduction pathway and transcriptional regulation during SEM (Zuo et al. 2002; Gaj et al. 2005; aan den Toorn et al. 2015; Podio et al. 2014). LEC1, LEC2 and FUS3 are the key genes controlling the SEM process in plants (Gaj et al. 2005; Fambrini et al. 2006). The SEM capacity was completely repressed in double (lecl lec2, lec1 fus3, or lec2 fus3) and triple (lec1 lec2 fus3) Arabidopsis thaliana mutants (Gaj et al. 2005). The expression level of LEC2/FUS changed rapidly in response to auxin treatment (Stone et al. 2008), suggesting that $L E C / F U S$ may be the upstream genes in the auxin signaling pathway (Gaj et al. 2005; Stone et al. 2001). According to our proteomic profile, these SEM related proteins were differentially accumulated during cotton SEM (Table 3). Both SERK and LEC proteins were up-regulated in EC and SEs compared with NEC. These two types of proteins are multifunctional regulators in both zygotic and SEM with a role in hormone signaling and stress responses (Mahdavi-Darvari et al. 2015), and have been used as markers of totipotency in plant species. CASEIN KINASE I, which have been previously demonstrated to play a role in SEM of cotton and other
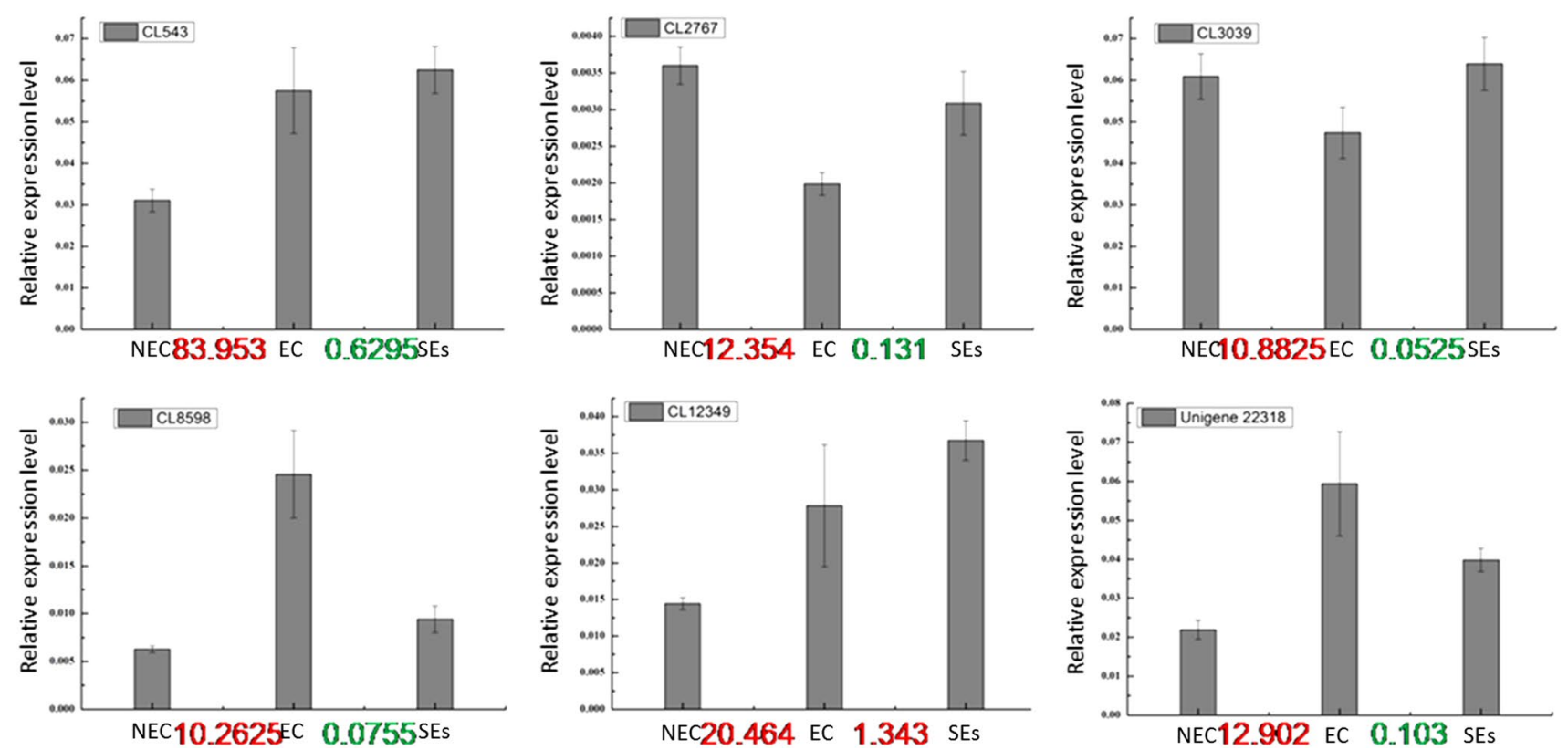

Fig. 6 Transcriptional analysis of candidate genes encoding for the DAPs the numbers showing on the $\mathrm{X}$-axis are the fold changes of the accumulated level of the corresponding DAP in EC versus NEC and
SEs versus EC based on the iTRAQ data. Red and green denote up and down regulation, respectively 
Table 3 Fold changes of selected DAPs in NEC vs. EC and EC vs. SEs

\begin{tabular}{|c|c|c|c|c|c|}
\hline No. & Protein ID & Protein name & Pathway annotation in KEGG & NEC vs. EC & EC vs. SEs \\
\hline 1 & CL2809.Contig4_All & GH3 & Auxin signal & -1.8 & 0.6 \\
\hline 2 & CL2472.Contig1_All & CRE1 & CTK signal & 2.7 & -3.1 \\
\hline 3 & Unigene20442_All & AHP & CTK signal & - & 0.8 \\
\hline 4 & CL11792.Contig4_All & B-ARR & CTK signal & 1.8 & -1.6 \\
\hline 5 & Unigene12438_All & DELLA & Gibberellin signal & - & -1.1 \\
\hline 6 & Unigene13500_All & GID & Gibberellin signal & 1.8 & - \\
\hline 7 & CL1027.Contig3_All & $\mathrm{ABF}$ & ABA signal & 2.7 & -2 \\
\hline 8 & CL5280.Contig2_All & PYR/PYL & ABA signal & - & 1.5 \\
\hline 9 & CL7181.Contig7_All & CTR1 & Ethylene signal & 0.8 & -0.9 \\
\hline 10 & CL4433.Contig1_All & MPK6 & Ethylene signal & -0.7 & - \\
\hline 11 & CL12267.Contig1_All & BAK1 & Brassinosteroid signal & -1.6 & -2.6 \\
\hline 12 & CL10648.Contig2_All & BRI1 & Brassinosteroid signal & -0.8 & -2.3 \\
\hline 13 & CL7395.Contig2_All & TCH4 & Brassinosteroid signal & - & 0.8 \\
\hline 14 & Unigene11483_All & PR1 & SA signal & -2.8 & - \\
\hline 15 & CL12586.Contig1_All & SERK & Somatic embryogenesis related proteins & 4.8 & 3.7 \\
\hline 16 & CL7993.Contig1_All & LEC & Somatic embryogenesis related proteins & 2.2 & 1.7 \\
\hline 17 & CL4025.Contig1_All & CKI & Somatic embryogenesis related proteins & -1.4 & -1.1 \\
\hline 18 & CL11109.Contig1_All & ADC & Polyamines & 2.9 & 3.7 \\
\hline 19 & Unigene7615_All & SAMDC & Polyamines & 3.1 & 2.8 \\
\hline 20 & CL1916.Contig10_All & SPMS & Polyamines & 1.7 & 2.3 \\
\hline 21 & CL2833.Contig2_All & CAT & Peroxisome & 1.7 & -2.1 \\
\hline 22 & CL517.Contig2_All & SOD & Peroxisome & -1.6 & -2.2 \\
\hline 23 & CL600.Contig1_All & $\mathrm{FabF}$ & Fatty acid & 2.5 & - \\
\hline 24 & CL1721.Contig2_All & FatA & Fatty acid & 1.4 & - \\
\hline 25 & Unigene19300_All & FabG & Fatty acid & - & 1.8 \\
\hline 26 & Unigene7832_All & FabZ & Fatty acid & - & 0.7 \\
\hline 27 & Unigene9530_All & SERK & Transcription factor & 1.8 & 2.4 \\
\hline 28 & CL11093.Contig1_All & LEC1 & Transcription factor & 1.7 & 3.1 \\
\hline 29 & Unigene10107_All & WUS & Transcription factor & 4.1 & 4.1 \\
\hline 30 & CL7829.Contig6_All & CKI & Transcription factor & 2.8 & -1.9 \\
\hline 31 & CL11268.Contig2_All & ND1 & Oxidative phosphorylation & 3 & 1 \\
\hline 32 & CL4559.Contig2_All & ND6 & Oxidative phosphorylation & 8.2 & 3.7 \\
\hline 33 & CL3850.Contig1_All & COX3 & Oxidative phosphorylation & 14.4 & 12.9 \\
\hline 34 & CL4756.Contig1_All & COX15 & Oxidative phosphorylation & 1.2 & 1.4 \\
\hline 36 & CL7474.Contig1_All & $C D P K$ & Stress-response & 2.9 & -3.2 \\
\hline 37 & CL10919.Contig1_All & HSP90 & Stress-response & 6.8 & -1.3 \\
\hline 38 & Unigene15666_All & $S G T 1$ & Stress-response & 2.2 & 2.3 \\
\hline 39 & CL4692.Contig1_All & $4 C L$ & Secondary metabolites & -1.9 & 2.4 \\
\hline
\end{tabular}

plants, was down-regulated in EC and SEs compared with NEC (Table 3), consistent with the previously published result in cotton (Mahdavi-Darvari et al. 2015). GhCKI is a negative regulator of cotton SEM by regulating auxin homeostasis through the LEC1-CKI-TCP15-PIF4 network (Min et al. 2015). Our data thus confirmed the possible role of SERK, LEC and CKI during cotton SEM.

\section{Plant hormone signal transduction involved in cotton somatic embryogenesis}

Plant hormones played important roles in SEM either working alone or through crosstalk with each other (Yang and Zhang 2010; Yang et al. 2012; Xu et al. 2013; Cheng et al. 2016). Based on our proteome profile, a number of proteins 
related to hormone (including auxin, cytokinine, gibberellin, ABA, ethylene, brassinosteroid and SA) metabolism and signaling pathways were differentially expressed in EC and/ or SEs.

The regulatory role of these proteins was probably achieved by establishing auxin and cytokinine gradients during the induction phase of SEM. They are essential for initiating dedifferentiation and cell division of already differentiated cells before they could express embryogenic competence. Despite the absolute requirement for exogenous auxin to sustain growth of plant cells cultured in vitro, cultured plant cells produce substantial amounts of the native auxin, IAA. Comprehensive studies have been conducted on callogenesis from several cotton cultivars using various explants, and different combinations of growth regulators. We found that $\mathrm{GH} 3$, an auxin-induced protein involved in the auxin signal pathway, was differentially expressed in NEC, EC and SEs (Table 3). GH3 was down-regulated in EC but up-regulated in SE, consistent with the result of low concentration of auxin promoting EC differentiation in cotton (Sun et al. 2006; Zhou et al. 2016).

Cytokinine induces SEM and plant regeneration in many plant species (Wang and Chong 2015). Proteins involved in the cytokinine signal pathway, such as CRE1 (a cytokinin receptor), AHP and B-ARR, showed a differentially expressed pattern in EC and/or SEs. Compared with NEC, EC had an up-regulated level of both CRE1 and B-ARR, and compared with EC, SEs had a down-regulated level of both CRE1 and B-ARR. AHP was unchanged between NEC and EC but slightly up-regulated in SEs (Table 3).

In the gibberellin signal pathway, GID1 and DELLA showed differential and opposite expression pattern in NEC versus EC and EC versus SEs. From NEC to EC, GID1 was up-regulated and then remained unchanged in SEs. In contrast, from NEC to EC, the level of DELLA was unchanged but was then down-regulated in SEs.

Abscisic acid plays an important role in the accumulation of nutritive products during the development and maturation of asexual embryo (Jin et al. 2014). PYR/PYL and ABF, involved in the ABA signal pathway, showed differential expression pattern during cotton somatic embryogenesis. From NEC to SEs, ABF was up-regulated in EC and then down-regulated in SEs. The level of PYR/PYL showed no significant difference between NEC and EC, and was upregulated in SEs compared to EC.

The role of ethylene on embryogenic induction is complicated by its inconsistent effects in different plants and culture systems. In our study, CTR1, which is involved in the ethylene signal pathway, was slightly down-regulated in SEs compared to EC, suggesting a possible negative role of CTR1 in cotton SEM.

Brassinosteroids (BRs) are growth-promoting steroid hormones that occur widely across the plant kingdom and regulate multiple aspects of physiological responses essential for both vegetative and reproductive development (Clouse 2011). Proteins like BAK1 and BRI1, involved in the brassinosteroid signal pathway, were mostly down-regulated in both NEC versus EC and EC versus SEs.

PR-1, involved in the salicylic acid signal pathway, was down-regulated in EC compared to NEC and then remained unchanged in SEs. These results of hormone signaling related proteins demonstrated an essential role of hormones and their complicated crosstalk in cotton SEM.

\section{Polyamines involved in cotton somatic embryogenesis}

Polyamines have been shown to be involved in many physiological processes including regulation of cell division, senescence, responses to both biotic and abiotic stress (Marco et al. 2011; Minocha et al. 2014). Based on KEGG analysis and GO annotation, proteins involved in polyamine synthesis or metabolism, including SAMDC, ADC and SPMS, were all differentially expressed during cotton SEM. All of these proteins showed a higher expression level in EC compared with NEC and continued to increase in SEs (Table 3; Fig. 5), consistent with our recent transcriptome results showing that polyamines could promote cotton SEM (Cheng et al. 2015, 2016). Both ADC mRNA and protein were localized in dividing cells of embryo meristems, probably required for mitosis (Vuosku et al. 2006). Exogenous application of Put and Spm enhanced the growth of embryogenic cultures of Araucaria angustifolia and significantly affected the endogenous concentrations of PAs, IAA and ABA in embryogenic tissues (Steiner et al. 2007). Our previous results also showed that exogenous application of polyamines enhanced the growth and development of cotton SEs, which could be achieved by PAs-mediated regulation of specific physiological processes important for cellular differentiation (Cheng et al. 2016).

\section{Cotton somatic embryogenesis regulated by reactive oxygen species (ROS)}

The NADH dehydrogenase related proteins, ND1 and ND6, were up-regulated in EC and SEs compared to NEC. The cytochrome $\mathrm{C}$ oxidases, including COX3 and COX15, showed an up-regulated pattern in EC and SEs. The ATPases (includes $\mathrm{A}, \mathrm{F}$ and $\mathrm{V}$-type) had a relatively high expression level in EC (Table 3). Differential expression of proteins related to oxidative phosphorylation indicated that energy metabolism was very active in the transition from NEC to $\mathrm{EC}$ and development of SEs.

Additionally, proteins involved in the protective system, including CAT and SOD, were up-regulated in EC and SEs (Table 3). The antioxidant system might play a role in 
maintaining ROS homeostasis during the differentiation and development of EC and SEs. These results suggested that ROS played a crucial role in the development of EC and SEs during cotton SEM.

The stress response related proteins, such as CDPK, HSP90 and SGT, were also differentially expressed during cotton SEM (Table 3), suggesting that stresses might be involved in regulating EC proliferation and differentiation of SEs.

These results indicated that ROS was closely related to cotton somatic embryogenesis, and as signal molecules, the role of ROS in regulating SE was unclear. A recent research reported that the ROS homeostasis might regulate somatic embryogenesis via the regulation of auxin signaling in Cotton (Zhou et al. 2016).

\section{Fatty acid biosynthesis and metabolism in cotton somatic embryogenesis}

The composition of fatty acid rapidly changed during somatic embryo development following the induction of embryogenesis in D. carota (Warren and Fowler 1979; Makarenko et al. 2016). In our iTRAQ profile, many fatty acid biosynthesis and metabolism related proteins, such as $\mathrm{FabH}$, accC, FatB and FabD, were differentially accumulated. In the fatty acid biosynthesis pathway, $\mathrm{FabH}$, accC, FatB and FabD were up-regulated in both EC and SEs (Table 3). A previous study reported that ectopic expression of $L E C 2$ induces accumulation of fatty acid during the maturation phase of embryogenesis (Stone et al. 2008). These results indicated that fatty acid might play an important role in cotton SEM.

\section{Genetic information rapidly changed during somatic embryogenesis}

Cellular dedifferentiation and redifferentiation are the two important events during plant regeneration via SEM (Yang and Zhang 2010; Zimmerman 1993). In this study, we found that many DAPs are directly or indirectly involved in genetic information processing, including transcription, post-transcription, translation and post-translation. Five of the top 10 pathways of DAPs (including $19.63 \%$ of all DAPs) were annotated as related to genetic information processing pathways. These DAPs exhibited opposite expression pattern in NEC vs EC and EC versus SE, i.e. down-regulated in EC formation and up-regulated in SE differentiation (data not shown). These results suggested that some structural genes might be down-regulated to save energy during cellular dedifferentiation and subsequently were alternatively expressed during cellular redifferentiation through rapid genetic information processing (Noah et al. 2013).
Secondary metabolites broadly involved in somatic embryogenesis

Secondary metabolites, including terpene, phenolic and nitrogen-containing compound, are widely involved in growth, development and defense and play important roles in plant life cycle (Bartwal et al. 2013; Chacón et al. 2013). According to the KEGG pathway annotation, $17.64 \%$ of all DAPs were found to be involved in biosynthesis of secondary metabolites. Actually, plant tissue culture process was accompanied by a large number of metabolism and transport. Although the precise function of a certain secondary metabolite was still unclear, our findings provided foundation for further studies. For example, we found that $4 \mathrm{CL}$ (4-coumarate-CoA-ligase), one of the key enzymes involved in phenylpropanoid metabolism and lignin biosynthesis, was reversely expressed during differentiation of EC and SE, suggesting that lignin and related metabolites might function differently during EC formation and SE development.

\section{Correlation analysis of transcriptome and proteome data}

To better understand the relationship and interplay between transcriptome and proteome in cotton SEM, we did correlation analysis using the transcriptome data we previously generated from the same samples (Cheng et al. 2016) and the proteome data generated in this study. The analysis was performed at three different levels, i.e. based on the number of proteins and transcripts identified (Identification), the number of proteins and transcripts that could be quantified (Quantification) and the number of proteins and transcripts differentially expressed (Differential expression) (Table 4). The number of identified proteins was based on the iTRAQ qualitative screen results. The proteins represented by two or more peptides were considered as quantifiable, for which the peptide ratio was calculated, and the median peptide ratio was used to represent the corresponding protein level. The criteria of differentially expressed proteins have been mentioned above. The $\mathrm{P}$ value for differentially expressed genes was 0.001 . As a result, almost all identified and quantifiable proteins (>99\%) had a corresponding transcript, but only $18.6 \%(160 / 858), 56.3 \%$ (576/1024) and 53.9\% (263/488) of DAPs had a corresponding differentially expressed transcript in EC vs. SEs, NEC vs. EC and NEC vs. SEs, respectively (Table 4). These results indicate that the presence of a protein was well supported by the presence of a corresponding transcript, but the correlation between the expression level or change of a protein and its corresponding transcript is poor and seems to be tissue and developmental stage dependent. This was further supported by the low correlation coefficient between the changes of proteins and their corresponding transcripts in the three samples. For example, 
Table 4 Correlation analyses of transcripts and proteins

\begin{tabular}{llccc}
\hline Comparison group & Level & $\begin{array}{l}\text { Number of } \\
\text { proteins }\end{array}$ & $\begin{array}{l}\text { Number of } \\
\text { transcripts }\end{array}$ & $\begin{array}{l}\text { Number of proteins with a } \\
\text { corresponding transcript }\end{array}$ \\
\hline EC vs. SEs & Identification & 5892 & 87,790 & 5831 \\
EC vs. SEs & Quantitation & 4080 & 87,790 & 4061 \\
EC vs. SEs & Differential expression & 858 & 11,888 & 160 \\
NEC vs. EC & Identification & 5892 & 100,750 & 5885 \\
NEC vs. EC & Quantitation & 4077 & 100,750 & 4075 \\
NEC vs. EC & Differential expression & 1024 & 42,532 & 576 \\
NEC vs. SEs & Identification & 5892 & 100,509 & 5883 \\
NEC vs. SEs & Quantitation & 4086 & 100,509 & 4082 \\
NEC vs. SEs & Differential expression & 488 & 29,408 & 263 \\
\hline
\end{tabular}

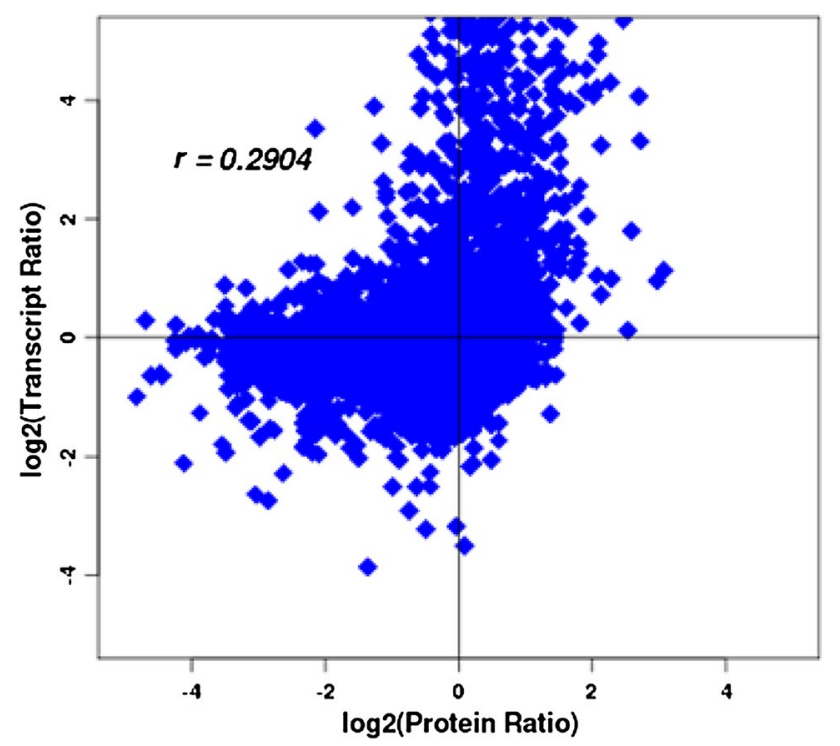

Fig. 7 Correlation of changes of protein accumulation and gene expression in NEC versus EC

the correlation coefficient between the changes of protein and its corresponding transcript in NEC vs. EC was 0.29 (Fig. 7). These results suggest that analysis of both transcriptome and proteome is required to identify key players critical for cotton SEM. To support this notion, the gene expression levels of about a third of the DAPs listed in Table 4 were also significantly different in the three developmental stages (Jiménez and Thomas 2006), and these genes had a good correlation between the changes of transcript and protein.

\section{Conclusion}

In conclusion, our proteomics analysis unveiled the complex and dynamic nature of the protein network involved in cell dedifferentiation and redifferentiation during cotton SEM, and identified the key regulators for cotton SEM. Our proteomics results confirmed our previous transcriptomic results on the role of the polyamine metabolic pathways and stress responses in cotton SEM. We propose that SEM related proteins are the top layer players regulating reprogramming of the transcriptome required for cell dedifferentiation and redifferentiation, and that the hormone synthesis and signaling pathways, the stress-response pathways and the polyamine metabolic pathways function side-by-side and synergistically to promote embryogenic cell initiation, somatic embryogenesis and plantlet regeneration. The possible role of certain genes/proteins and pathways regulating cotton SEM will be further investigated in our future work.

Acknowledgements This work was supported by the National Key Research and Development Program of China (Grant No. 2016YFD0100200), Special Program of Xinjiang Production and Construction Croups: Germplasm Functional Gene Discovery (Grant No. 2012BB049). Natural Science Foundation of Hubei Province of China (2017CFB162).

Author contributions Conceived and designed the experiments: WHC, HGZ and JS. Performed the experiments: WHC, WGT, YJL, FL, FX. Analyzed the data: WHC, HGZ. Contributed reagents/materials/analysis tools: JS, YQS. Wrote the paper: WHC, YQS and QHZ.

\section{Compliance with ethical standards}

Conflict of interest The authors declare that the research was conducted in the absence of any commercial or financial relationships that could be construed as a potential conflict of interest.

Open Access This article is distributed under the terms of the Creative Commons Attribution 4.0 International License (http://creativecommons.org/licenses/by/4.0/), which permits unrestricted use, distribution, and reproduction in any medium, provided you give appropriate credit to the original author(s) and the source, provide a link to the Creative Commons license, and indicate if changes were made. 


\section{References}

aan den Toorn M, Albrecht C, de Vries S (2015) On the origin of SERKs: bioinformatics analysis of the somatic embryogenesis receptor kinases. Mol Plant 8:762-782

Bartwal A, Mall R, Lohani P, Guru S, Arora S (2013) Role of secondary metabolites and brassinosteroids in plant defense against environmental stresses. J Plant Growth Regul 32:216-232

Bian F, Zheng C, Qu F, Gong X, You C (2010) Proteomic analysis of somatic embryogenesis in Cyclamen persicum Mill. Plant Mol Biol Rep 28:22-31

Bogs J, Downey MO, Harvey JS, Ashton AR, Tanner GJ, Robinson SP (2005) Proanthocyanidin synthesis and expression of genes encoding leucoanthocyanidin reductase and anthocyanidin reductase in developing grape berries and grapevine leaves. Plant Physiol 139:652-663

Chacón ID, Riley-Saldaña CA, González-Esquinca AR (2013) Secondary metabolites during early development in plants. Phytochem Rev 12:47-64

Cheng W-H, Wang F-L, Cheng X-Q, Zhu Q-H, Sun Y-Q, Zhu H-G, Sun J (2015) Polyamine and its metabolite $\mathrm{H}_{2} \mathrm{O}_{2}$ play a key role in the conversion of embryogenic callus into somatic embryos in upland cotton (Gossypium hirsutum L.). Front Plant Sci 6:1063

Cheng WH, Zhu HG, Tian WG, Zhu SH, Xiong XP, Sun YQ, Zhu QH, Sun J (2016) De novo transcriptome analysis reveals insights into dynamic homeostasis regulation of somatic embryogenesis in upland cotton (G. hirsutum L.). Plant Mol Biol 92:279-292

Clouse SD (2011) Brassinosteroid signal transduction: from receptor kinase activation to transcriptional networks regulating plant development. Plant Cell 23:1219-1230

Fambrini M, Durante C, Cionini G, Geri C, Giorgetti L, Michelotti V, Salvini M, Pugliesi C (2006) Characterization of LEAFY COTYLEDON1-LIKE gene in Helianthus annuus and its relationship with zygotic and somatic embryogenesis. Dev Genes Evol 216:253-264

Gaj MD, Zhang S, Harada JJ, Lemaux PG (2005) Leafy cotyledon genes are essential for induction of somatic embryogenesis of Arabidopsis. Planta 222:977-988

Ge X, Zhang C, Wang Q, Yang Z, Wang Y, Zhang X, Wu Z, Hou Y, Wu J, Li F (2014) iTRAQ protein profile differential analysis between somatic globular and cotyledonary embryos reveals stress, hormone, and respiration involved in increasing plantlet regeneration of Gossypium hirsutum L. J Proteome Res 14:268-278

Heringer AS, Barroso T, Macedo AF, Santa-Catarina C, Souza GHMF, Floh EIS, de Souza-Filho GA, Silveira V (2015) Label-free quantitative proteomics of embryogenic and non-embryogenic callus during sugarcane somatic embryogenesis. PLoS ONE 10:e0127803

Jiménez VM (2005) Involvement of plant hormones and plant growth regulators on in vitro somatic embryogenesis. Plant Growth Regul 47:91-110

Jiménez VM, Thomas C (2006) Participation of plant hormones in determination and progression of somatic embryogenesis. In Mujib A, Šamaj J (ed) Somatic embryogenesis, Springer, New York, pp 103-118

Jin F, Hu L, Yuan D, Xu J, Gao W, He L, Yang X, Zhang X (2014) Comparative transcriptome analysis between somatic embryos (SEs) and zygotic embryos in cotton: evidence for stress response functions in SE development. Plant Biotechnol J 12:161-173

Kulinska-Lukaszek K, Tobojka M, Adamiok A, Kurczynska E (2012) Expression of the BBM gene during somatic embryogenesis of Arabidopsis thaliana. Biol Plant 56:389-394

Letarte J, Simion E, Miner M, Kasha KJ (2006) Arabinogalactans and arabinogalactan-proteins induce embryogenesis in wheat (Triticum aestivum L.) microspore culture. Plant Cell Rep 24:691-698
Luo M, Xiao Y-H, Hou L, Luo X-Y, Li D-M, Pei Y (2003) [Cloning and expression analysis of a LIM-domain protein gene from cotton (Gossypium hirsuturm L.)]. Yi chuan xue bao $=$ Acta genetica Sinica 30:175-182

Mahdavi-Darvari F, Noor NM, Ismanizan I (2015) Epigenetic regulation and gene markers as signals of early somatic embryogenesis. Plant Cell Tissue Organ Cult 120:407-422

Makarenko SP, Shmakov VN, Dudareva LV, Stolbikova AV, Semenova NV, Tret'yakova IN, Konstantinov YM (2016) Fatty acid composition of total lipids in embryogenic and nonembryogenic callus lines of larch. Russ J Plant Physiol 63:252-258

Mantiri FR, Kurdyukov S, Lohar DP, Sharopova N, Saeed NA, Wang X-D, VandenBosch KA, Rose RJ (2008) The transcription factor MtSERF1 of the ERF subfamily identified by transcriptional profiling is required for somatic embryogenesis induced by auxin plus cytokinin in Medicago truncatula. Plant Physiol 146:1622-1636

Marco F, Alcázar R, Tiburcio AF, Carrasco P (2011) Interactions between polyamines and abiotic stress pathway responses unraveled by transcriptome analysis of polyamine overproducers. Omics 15:775-781

Min L, Hu Q, Li Y, Xu J, Ma Y, Zhu L, Yang X, Zhang X (2015) LEAFY COTYLEDON1-CASEIN KINASE I-TCP15-PHYTOCHROME INTERACTING FACTOR4 network regulates somatic embryogenesis by regulating auxin homeostasis. Plant Physiol 169:2805-2821

Minocha R, Majumdar R, Minocha SC (2014) Polyamines and abiotic stress in plants: a complex relationship. Front Plant Sci 5:175

Murashige T, Skoog F (1962) A revised medium for rapid growth and bio assays with tobacco tissue cultures. Physiol Plant 15:473-497

Noah AM, Niemenak N, Sunderhaus S, Haase C, Omokolo DN, Winkelmann T, Braun H-P (2013) Comparative proteomic analysis of early somatic and zygotic embryogenesis in Theobroma cacao L. J Proteom 78:123-133

Podio M, Felitti SA, Siena LA, Delgado L, Mancini M, Seijo JG, González AM, Pessino SC, Ortiz JPA (2014) Characterization and expression analysis of SOMATIC EMBRYOGENESIS RECEPTOR KINASE (SERK) genes in sexual and apomictic Paspalum notatum. Plant Mol Biol 84:479-495

Schmidt E, Guzzo F, Toonen M, De Vries S (1997) A leucine-rich repeat containing receptor-like kinase marks somatic plant cells competent to form embryos. Development 124:2049-2062

Singla B, Tyagi AK, Khurana JP, Khurana P (2007) Analysis of expression profile of selected genes expressed during auxininduced somatic embryogenesis in leaf base system of wheat (Triticum aestivum) and their possible interactions. Plant Mol Biol 65:677-692

Steiner N, Santa-Catarina C, Silveira V, Floh EI, Guerra MP (2007) Polyamine effects on growth and endogenous hormones levels in Araucaria angustifolia embryogenic cultures. Plant Cell Tissue Organ Cult 89:55-62

Stone SL, Kwong LW, Yee KM, Pelletier J, Lepiniec L, Fischer RL, Goldberg RB, Harada JJ (2001) LEAFY COTYLEDON2 encodes a B3 domain transcription factor that induces embryo development. Proc Natl Acad Sci 98:11806-11811

Stone SL, Braybrook SA, Paula SL, Kwong LW, Meuser J, Pelletier J, Hsieh T-F, Fischer RL, Goldberg RB, Harada JJ (2008) Arabidopsis LEAFY COTYLEDON2 induces maturation traits and auxin activity: implications for somatic embryogenesis. Proc Natl Acad Sci 105:3151-3156

Sun Y, Zhang X, Huang C, Guo X, Nie Y (2006) Somatic embryogenesis and plant regeneration from different wild diploid cotton (Gossypium) species. Plant Cell Rep 25:289-296

Sun L, Wu Y, Zou H, Su S, Li S, Shan X, Xi J, Yuan Y (2013) Comparative proteomic analysis of the H99 inbred maize (Zea mays L.) line in embryogenic and non-embryogenic callus during somatic embryogenesis. Plant Cell Tissue Organ Cult 113:103-119 
Tan BC, Chin CF, Liddell S, Alderson P (2013) Proteomic analysis of callus development in Vanilla planifolia andrews. Plant Mol Biol Rep 31:1220-1229

Thomas C, Bronner R, Molinier J, Prinsen E, van Onckelen H, Hahne G (2002) Immuno-cytochemical localization of indole-3-acetic acid during induction of somatic embryogenesis in cultured sunflower embryos. Planta 215:577-583

Vale EM, Heringer AS, Barroso T, Ferreira AT, da Costa MN, Perales JEA, Santa-Catarina C, Silveira V (2014) Comparative proteomic analysis of somatic embryo maturation in Carica papaya L. Proteome Sci 12:37

Vuosku J, Jokela A, Läärä E, Sääskilahti M, Muilu R, Sutela S, Altabella T, Sarjala T, Häggman H (2006) Consistency of polyamine profiles and expression of arginine decarboxylase in mitosis during zygotic embryogenesis of Scots pine. Plant Physiol 142:1027-1038

Wang L, Chong K (2015) The essential role of cytokinin signaling in root apical meristem formation during somatic embryogenesis. Front Plant Sci 6:613-619

Warren G, Fowler M (1979) Changing fatty acid composition during somatic embryogenesis in cultures of Daucus carota. Planta 144:451-454

Wickramasuriya AM, Dunwell JM (2015) Global scale transcriptome analysis of Arabidopsis embryogenesis in vitro. BMC Genom 16:301

Xu Z, Zhang C, Zhang X, Liu C, Wu Z, Yang Z, Zhou K, Yang X, Li F (2013) Transcriptome profiling reveals auxin and cytokinin regulating somatic embryogenesis in different sister lines of cotton cultivar CCRI24. J Integr Plant Biol 55:631-642

Xu Z, Zhang C, Ge X, Wang N, Zhou K, Yang X, Wu Z, Zhang X, Liu C, Yang Z (2015) Construction of a high-density linkage map and mapping quantitative trait loci for somatic embryogenesis using leaf petioles as explants in upland cotton (Gossypium hirsutum L.). Plant Cell Rep 34:1-11

Yang X, Zhang X (2010) Regulation of somatic embryogenesis in higher plants. Crit Rev Plant Sci 29:36-57
Yang X, Zhang X, Yuan D, Jin F, Zhang Y, Xu J (2012) Transcript profiling reveals complex auxin signalling pathway and transcription regulation involved in dedifferentiation and redifferentiation during somatic embryogenesis in cotton. BMC Plant biology 12:110

Yang Z, Li C, Wang Y, Zhang C, Wu Z, Zhang X, Liu C, Li F (2014) GhAGL15s, preferentially expressed during somatic embryogenesis, promote embryogenic callus formation in cotton (Gossypium hirsutum L.). Mol Genet Genom 289:873-883

Zeng F, Zhang X, Cheng L, Hu L, Zhu L, Cao J, Guo X (2007) A draft gene regulatory network for cellular totipotency reprogramming during plant somatic embryogenesis. Genomics 90:620-628

Zhang C, Yu S, Fan S, Zhang J, Li F (2011) Inheritance of somatic embryogenesis using leaf petioles as explants in upland cotton. Euphytica 181:55-63

Zhang T, Hu Y, Jiang W, Fang L, Guan X, Chen J, Zhang J, Saski CA, Scheffler BE, Stelly DM (2015) Sequencing of allotetraploid cotton (Gossypium hirsutum L. acc. TM-1) provides a resource for fiber improvement. Nature Biotechnol 33:531-537

Zhao J, Wang B, Wang X, Zhang Y, Dong M, Zhang J (2015) iTRAQbased comparative proteomic analysis of embryogenic and nonembryogenic tissues of Prince Rupprecht's larch (Larix principisrupprechtii Mayr). Plant Cell Tissue Organ Cult 120:655-669

Zheng Q, Zheng Y, Perry SE (2013) AGAMOUS-Like15 promotes somatic embryogenesis in Arabidopsis and soybean in part by the control of ethylene biosynthesis and response. Plant Physiol 161:2113-2127

Zhou T, Yang X, Guo K, Deng J, Xu J, Gao W, Lindsey K, Zhang X (2016) ROS homeostasis regulates somatic embryogenesis via the regulation of auxin signaling in cotton. Mol Cell Proteom 15:2108

Zimmerman JL (1993) Somatic embryogenesis: a model for early development in higher plants. Plant Cell 5:1411

Zuo J, Niu QW, Frugis G, Chua NH (2002) The WUSCHEL gene promotes vegetative-to-embryonic transition in Arabidopsis. Plant J 30:349-359

\section{Affiliations}

\section{Hua-Guo Zhu ${ }^{1} \cdot$ Wen-Han Cheng ${ }^{1,4} \cdot$ Wen-Gang Tian ${ }^{1} \cdot$ Yang-Jun Li $^{1} \cdot$ Feng Liu ${ }^{1} \cdot$ Fei Xue ${ }^{1} \cdot$ Qian-Hao Zhu ${ }^{2}$. Yu-Qiang Sun ${ }^{1,3} \cdot$ Jie Sun $^{1}$}

\section{Hua-Guo Zhu}

zhgroger@sohu.com

Wen-Han Cheng

kaven_53@163.com

1 College of Agriculture/The Key Laboratory of Oasis Eco-Agriculture, Shihezi University, Shihezi 832000, Xinjiang, China
2 CSIRO Agriculture and Food, GPO Box 1700, Canberra, ACT 2601, Australia

3 College of Life Sciences, Key Laboratory of Plant Secondary Metabolism and Regulation of Zhejiang Province, Zhejiang Sci-Tech University, Hangzhou 310018, Zhejiang, China

4 Jingchu University of Technology, Jingmen 448000, Hubei, China 